\title{
MODEL IBADAH DALAM TINJAUAN TAFSIR IZWAJI
}

\author{
Musthofa \\ Sekolah Tinggi Agama Islam (STAI) Madiun \\ Email: mustofa030858@gmail.com
}

\begin{abstract}
Worship according to the view of understanding the science of jurisprudence can be divided into two, namely mahdah worship, worship that is still pure setting of procedures, place and time and gairu mahdah worship, which is a model of worship that is not regulated by procedures, determination of time and place by sharia. The model of mahdah worship is prescribed: (1) bound by place, time and procedure, (2) bound by procedure, (3) bound by time limit on the circulation of the sun/moon. (4) Bound by procedure but not bound by time, place. The model of worship of gairu mahdah is a form of worship that is not pure in bond with Islamic law, both place, time and procedure (unless prescribed). Ibadah mahdah which is bound by place, time and procedure such as Hajj, is bound by time and procedure such as prayer, which is bound by procedure such as absolute sunnah fasting, Hajj. Gairu mahdah such as zikir, shadaqah, devotion to both parents.
\end{abstract}

Keywords: model, ibadah, mahdah, gairu mahdah.

\section{Abstrak}

Ibadah menurut pandangan pemahaman ilmu fiqih dapat dibagi menjadi dua yaitu ibadah mahdah, ibadah yang masih murni pengaturan tatacara, 
tempat dan waktunya dan ibadah gairu mahdah yaitu model ibadah yang tidak diatur tatacara, penentuan waktu dan tempatnya oleh syariat. Model ibadah mahdah disyariatkan: (1) terikat tempat, waktu dan tatacaranya, (2) Terikat tatacaranya, (3) terikat batasan waktu atas peredaran mataharil bulan. (4) Terikat tatacaranya tetapi tidak terikat waktu, tempatnya. Model ibadah gairu mahdah adalah bentuk ibadah yang tidak murni dalam ikatan pada syariat Islam, baik tempat, waktu maupun tatacaranya (kecuali disyariatkan). Ibadah mahdah yang terikat tempat, waktu dan tatacaranya seperti ibadah haji, terikat waktu dan tatacaranya seperti ibadah salat, yang terikat tatacaranya seperti ibadah puasa sunah mutlak, ibadah haji. Gairu mahdah misalnya zikir, shadaqah, berbakti kepada kedua orang tua.

Kata Kunci: model, ibadah, mahdah, gairu mahdah.

\section{PENDAHULUAN}

Ibadah adalah merupakan bentuk pengabdian seorang hamba pada Tuhan-nya. Ibadah memiliki model yang beragam, yaitu ibadah mahdah dan ibadah gairu mahdah. Masing-masing mempunyai bentuk pengamalan yang berbeda-beda sesuai dengan jenis ibadah itu sendiri. Namun tidak lepas dari tuntunan nas Al-Quran dan Al-Hadis. Sehingga Rasul SAW bersabda dalam sebuah hadis tentang contoh amalan ibadah berdoa atau membaca salawat. Ini telah diperintahkan dalam Al-Quran:

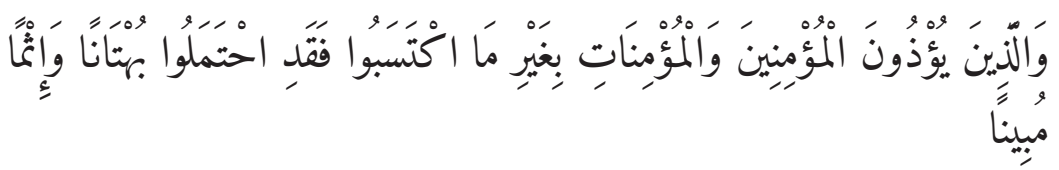

Artinya: Sesungguhnya Allah dan malaikat-malaikat-Nya bershalawat untuk Nabi. Hai orang-orang yang beriman, bershalawatlah kamu untuk Nabi dan ucapkanlah salam penghormatan kepadanya. ${ }^{1}$

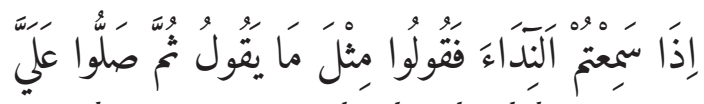

Artinya: Apabila kamu mendengar azan, maka katakanlah apa yang ia katakan, kemudian bersalawatkan kepadaku. ${ }^{2}$

Allah dan Rasul SAW memerintahkan membaca salawat. Di dalam perin-

${ }^{1}$ QS. Al-Ahzab (33): 56.

2 Imam Muslim, Sahih Muslim, Indonesia: Daru al-Ihya, tt, hal. 163. 
tahnya tidak dijelaskan lafad salawat sehingga lafad salawat dapat disusun sesuai dengan lafad yang dimaksud oleh seseorang yang membacanya. Sebenarnya yang pada intinya salawat adalah bentuk doa yang ditujukan kepada Nabi saw, sehingga salawat dilafadkan bentuk salawat ma'surah (bentuk salawat tersusun dari Nabi SAW dari segi lafadnya), sehingga pengamalan dengan model salawat matsurah tergolong ibadah mahdah.

Namun yang ada di lapangan, adanya model salawat yang disusun oleh para ulama seperti salawat badar, salawat burdah, salawat nariyah, dan sebagainya. Model salawat ini termasuk ibadah gairu mahdah, sehingga melahirkan permasalahan, "Bagaimana bentuk-bentuk ibadah dalam ajaran Islam”.

Artikel ini disusun terdari dari sumber data yang didapat dalam referensi Al-Quran, Al-Hadis dan pendapat para ulama atau para ahli yang berhubungan dengan pembahasan.

Artikel ini dianalisis dengan pendekatan Tafsir Izwaji, yaitu penjelasan yang didapat dari keterangan Al-Quran, Al-Hadis dan para ahli yang membidanginya.

Artikel ini disusun melalui sistematika, diawali dengan Pendahuluan, Tinjauan tentang Ibadah dan Model-model Ibadah, diakhiri dengan Kesimpulan.

\section{TINJAUAN TENTANG IBADAH}

\section{Pengertian Ibadah}

Ibadah berasal dari kata 'mengabdi' (menyembah) عبَد - يَعبد - عِبَادَة sehingga ibadah dapat disimpulkan penyerahan (pengabdián) diri kepada Allah atas dasar ketaatan dengan merasakan kehinaan diri pada Allah sebagai Tuhan-nya.

Menurut Ismail bin Abu Naser Hamad Al-Jauhari, ibadah ibadah berasal dari lafad ubudiyah, al-dhudlu dan ladzallul (penyerahan diri dan kerendahan hati). ${ }^{3}$

Menurut Al-Zajjad, ibadah artinya taat dan penyerahan diri. Maka ibadah dapat diartikan penyerahan diri, rendah hati dan taat kepada Allah SWT. ${ }^{4}$ Ibadah sudah ditetapkan dalam ayat Al-Quran:

3 Ismail Abu Naser bin Hamad Al-Jauhari Al-Sholah, Taju Al-Kughati, wa Sikahu AlArabiyah.

${ }^{4}$ Suarning Said, Wawasan Al-Qur'an Tentang Ibadah, Jurnal Syariah Dan Hukum Diktum, Volume 15, Nomor 1, Juni 2017 : 43 - 54. 


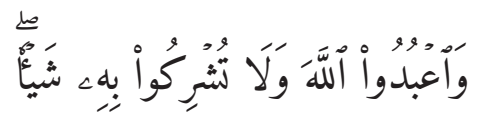

Artinya: Dan sembahlah Allah dan janganlah kamu mempersekutukan-Nya dengan sesuatupun. ${ }^{5}$

Ibadah di dalamnya mempunyai keutamaan yaitu berupa doa. Ini didasarkan hadis Nabi yang diriwayatkan oleh Al-Hakim:

Artinya: Lebih utamanya ibadah adalah doa. ${ }^{6}$

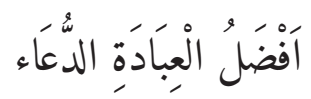

Ibadah, di dalamnya terdapat ruh (otak) yaitu berupa do'a. Ini didasarkan atas hadis Nabi, yang diriwayatkan oleh Iman Bukhari:

Artinya: Doa merupakan ruh (otak) dari ibadah.

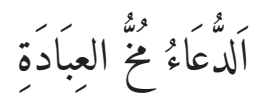

Ibadah di dalamnya terdapat nilai hakikat (sejatinya) yaitu do'a. Rasul pernah bersabda dalam hadisnya yang diriwayatkan oleh Imam Tirmidzi:

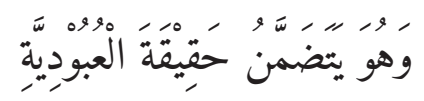

Artinya: Doa itu mengandung hakikat (sejatinya) peribadatan. ${ }^{7}$

Ibadah dapat diterima oleh Allah disyariatkan dengan dua hal yaitu:

a. Niat

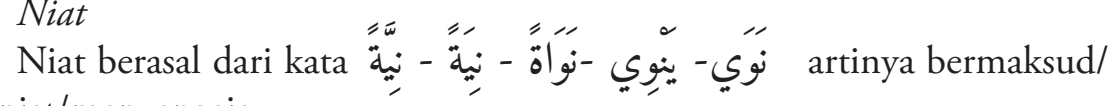
berniat/menyengaja.

Ibadah akan mendapatkan legitimasi (mendapatkan pengakuan) dari Allah diperlukan suatu syarat berupa niat yang didasari atas pengabdian atau ibadah kepada Allah. Rasul bersabda:

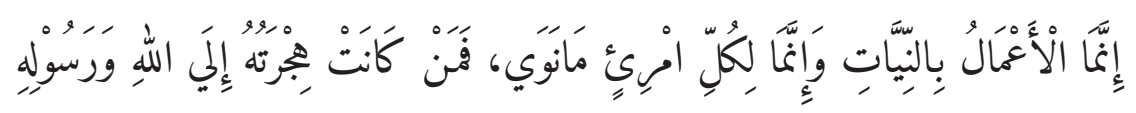

\footnotetext{
5 QS. An-Nisa (4): 36.

${ }^{6}$ Al-Imam Jalaluddin Abdu Arahman Abi Bakar Al-Suyuti, Al-Jamu'u Al-Shagir I, Bandung: Imdonesia, Syirkah Al-Ma'arif, tt, hal. 50.

7 Ibid, hal. 50.
} 


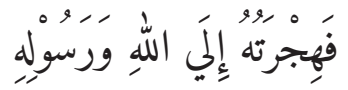

Artinya: Amal itu tergantung pada niatnya, sebenarnya setiap orang bergantung pada apa yang diniatkan, maka jika hijrahnya kepada Allah dan Rasul-Nya maka hijrah kepada Allah dan Rasul-Nya. ${ }^{8}$

Ibadah yang didasari pada niat seseorang dimaksudkan pada harapan atau kemurahan Allah, untuk memberi petunjuk pada hamba pada jalan menuju tempat yang kekal. ${ }^{9}$

Ibadah dalam bentuk amalan, pekerjaan apaun agar tidak sia-sia atau mendapatkan pengakuan (legitimasi) dari Allah, diwajibkan, mendasarinya dengan tujuan (niat). Ibadah ini telah disyariatkan bahwa dengan menjalankannya akan mendapat pahala, pahala ibadah diperoleh bukan karena amal atau perilaku ibadah itu sendiri, akan tetapi, pahala diperoleh atas dasar niatnya. Hal ini telah dituangkan dalam kitab Minahussaniyah bahwa Sayyid Khawas menganjurkan kepada muridnya, yang banyak ibadah niat ibadah salat malam, dengan pernyataannya sesungguhnya syara' sungguh telah menertibkan atas dasar niatnya bukan atas amal perbuatannya. ${ }^{10}$

Keterangan ini dapat diringkas bahwa ibadah adalah bentuk pengabdian kepada Allah didasari niat dengan harapan mendapat petunjuk dari Allah menuju tempat yang kekal (akhirat).

\section{b. Ikblas}

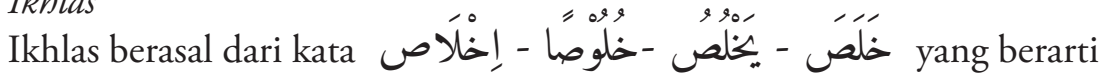
kejernihan, didasarkan atas firman Allah:

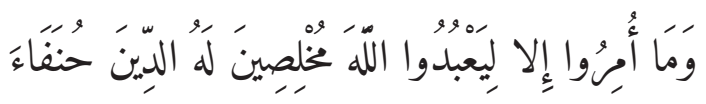

Artinya: Padahal mereka tidak disuruh kecuali supaya menyembah Allah dengan memurnikan ketaatan (tulus) kepada-Nya dalam (menjalankan) agama yang lurus. ${ }^{11}$

${ }^{8}$ Imam Muslim, Shahih Muslim I, Indonesia: Daru Al-Kitab Al-Arobiyah, tt, hal. 157158.

9 Al-Syeh Zainuddin bin Abdul Azis ibnu Zainuddin Al-Mulaibary, Irsyadu Al-Ibad, Semarang: Maktabah wa Matba'ah Thaha Putra, tt, hal. 2.

${ }^{10}$ Sayyid Abdul Wahab Al-Sya’roni, Munahussaniyah, Jakarta: Darul Ihya, tt, hal. 12.

${ }^{11}$ QS. Al-Bayyinah (98): 5. lihat Juga Nurlaili, Pendidikan Ibadah Dalam Al-Quran, ITTIHAD, Vol. I, No.2, Juli - Desember 2017 • P-Issn: 2549-9238• E-Issn: 25805541, 209-224 
Al-Maragi memberi penjelasan bahwa mereka berbeda dan berselisih, tidaklah mereka diperintah untuk kemaslakatan agama demi dunia mereka, yang menarik bagi mereka kebahagian, dalam kehidupan dan kembali mereka, dati ketulusan kepada Allah dalam keadaan rahasia maupun secara terang-terangan. ${ }^{12}$

Sehingga ibadah dapat diterima di hadapan Allah harus didasari niat yang diarahkan atas ridlo Allah, dengan tidak mengharapkan tambahan atau motivasi yang lain selain kepada Allah.

\section{Model Ibadah}

Model ibadah atas pemahaman Ilmu Fiqih pada Syariat Islami yang dinukil dari nas ayat-ayat Al-Quran dan Hadis Nabi SAW dipetakan menjadi dua macam, yaitu:

\section{a. Ibadah Mahdah}

Kata mahdah didapat dari kata

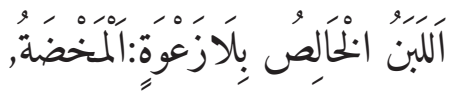

artinya: Al-mahdah: susu yang murni tanpa buih.

Ibadah mahdah berarti suatu bentuk ibadah kepada Allah dengan bentuk amalan-amalan yang masih murni, belum terdapat campuran (tambahan atau pengurangan). Ibadah mahdah yang bersifat murni yang diisyaratkan dalam Islam yang bersumber dari nas Al-Quran atau Al-Hadis, sehingga bentuk ibadah ini terikat pada: tempat, waktu dan tatacaranya, waktu dan batasan jam serta tatacaranya, terikat tatacaranya, terikat batasan waktu atas peredaran materi, terikat tatacaranya tetapi tidak terikat waktu dan tempatnya. ${ }^{13}$

1) Ibadah mahdah yang terikat tempat, waktu dan cara, seperti ibadah haji, di dalamnya petunjuk ibadah haji sudah ditentukan tempat yaitu mengunjungi Baitullah yang berada di Kota Mekah. Firman Allah:

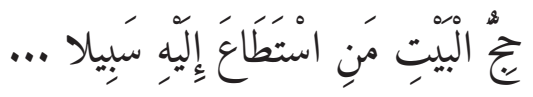

${ }^{12}$ Musthafa Al-Maragi, Tafsir Al-Maragi Juz 10, Darul Fikri, tt, hal.

${ }^{13}$ Marzuki, Kemitraan Madrasah Dan Orang Tua Dalam Menanamkan Kedisplinan Ibadah Siswa Ma Asysyafi'iyah Kendari, Jurnal Al-Ta'dib Vol. 10 No. 2, JuliDesember 2017, 163-180 
Artinya: Mengerjakan haji adalah kewajiban manusia terhadap Allah, yaitu (bagi) orang yang sanggup mengadakan perjalanan ke Baitullah. ${ }^{14}$

Ibadah haji bila dilakukan di luar Tanah Suci (Baitullah) mengakibatkan tidak dinyatakan sah menurut hukum Syara'.

Misalnya, ibadah haji disyari'atkan menetap atau berada di Padang Arafah yang dinamakan wukuf mulai tanggal 9 sampai dengan tanggal 10 Dzulhijjah, diawali dengan khutbah dilanjutkan salat fardu dengan jamak qashar. ${ }^{15}$

Jenis ibadah mahdah yang terikat tempat, waktu dan tatacara ibadah ini disyariatkan oleh agama Islam. Apabila ketiga syariat ini tidak terpenuhi mengakibatkan tidak dianggap sah.

Tatacara ibadah dapat diringkas, dimulai tanggal 8 Dzulhijjah mereka berangkat ke Mina, salah Zuhur, Ashar, Maghrib, Isya dan Subuh, sampai terbit matahari menuju ke Padang Arafah, di Arafah mulai waktu Zuhur, diawali dengan Azan dan Iqomah dilanjutkan salat Zuhur dan Ashar dengan jamak taqdim qashar.

Kemudian menuju Muzdalifah dengan menjalankan salat Maghrib dilakukan dengan jamak qashar. Kemudian menuju Mina dengan salat jamak qashar, dan melempar jumrah ula, wusta, dan aqabah.

Selanjutnya tawaf ifadhah di Masjidil Haram untuk mengelilingi Kabah 7 kali, dilanjutkan sai, diakhiri dengan tahalul. ${ }^{16}$

Ibadah ini apabila tidak memenuhi ketentuan tempat, waktu, dan tatacara yang ditentukan dianggap tidak sah oleh syariat, maka dinamakan mahdah tempat, waktu dan kaifiyahnya.

Model ibadah ini disyariatkan dengan tujuan agar umat Islam seluruh penjuru dunia, bermacam-macam suku, ras, adat, mereka dapat berkumpul pada tempat, waktu, tatacara ibadah yang sama. Ini merupakan maklumat tahunan bagi umat Islam dengan tujuan menjaga kerukunan umat Islam di seluruh dunia.

2) Ibadah Mahdah yang terikat waktu dengan batasan jam dan tatacaranya

\footnotetext{
${ }^{14}$ QS. Ali Imran (3): 97.

${ }^{15}$ Imam Abu Hamid Al-Gazali, Ihya Ulumuddin Juz I, Daru Ihya Al-Kutub Al-Arabiyah, tt, hal. 254.

${ }^{16}$ Al-Sayyid Al-Imam Ismail Al-Kahlany, kemudian Al-Shan'any, Subulus Salam Juz 2, Bandung: Multazam Taba'ah wa Al-Nasyrah, tt, hal. 199-200.
} 
Ibadah ini dapat dicontoh pada ibadah salat wajib lima waktu. Ini sudah ditentukan dan diakui tatacaranya. Seperti ringkasan dalam hadis Nabi saw. Waktu salat Zuhur, apabila lingsir matahari sampai bayangan seseorang sama ukuran dengan orang itu selama belum datang waktu Ashar. Waktu Ashar sampai mega matahari tidak kekuning-kuningan. Waktu Maghrib mulai terbenam matahari sampai mega merah. Waktu Isya mulai tenggelamnya mega sampai mulai waktu Subuh. Waktu Subuh mulai terbit fajar sampai terbitnya matahari. ${ }^{17}$

Kemudian tatacara salat sudah diatur oleh syariat Islam, yang diawali dengan tata cara tertentu, doawali niat, berdiri bagi yang mampu, takbiratul ikram, membaca fatihah, rukuk, tumakninah, bangun dari rukuk, iktidal, tumakninah, sujud, tumakninah dalam sujud, duduk diantara dua sujud, tumakninah, dan duduk terakhir tasyahud, membaca Salawat Nabi, taslim awal, niat keluar dari salat dan tertib rukun. ${ }^{18}$

Model ibadah ini akan dinilai absah oleh syariat apabila terpenuhi ketentuan waktu dan tatacaranya.

Model ibadah ini disyariatkan dengan tujuan agar seorang hamba menunjukkan sikap teguh dan ketaatannya kepada Tuhan-nya dalam satu hari dirutinkan jumlah minimum 5 (lima) kali pada waktu yang diatur agar mereka mengingat kepada Tuhan-nya pada waktu yang telah dijadwalkan.

3) Ibadah Mahdah terikat dengan tatacaranya saja

Ibadah yang dapat dilakukan dimana saja dan kapan saja (selama tidak ada lainnya) dengan tatacara yang ditentukan oleh syar'i. Misalnya puasa sunah mutlak, artinya suatu ibadah puasa sunah dilakukan dengan cara menahan makan dan minum serta bersenggama. Model ibadah ini tidak terikat bulan dan hari, tetapi dapat dilakukan kapan saja (selama tidak ada lainnya). Hal ini dilakukan oleh Rasul:

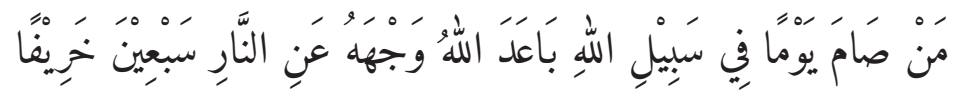

Artinya: Barangsiapa puasa satu hari di jalan Allah, maka Allah akan menjaubkan wajahnya dari neraka sejauh tujuh puluh tahun. ${ }^{19}$

\footnotetext{
${ }^{17}$ Imam Muslim, Op. Cit, hal. 236.

${ }^{18}$ Al-Imam Al-Alamah Ahmad bin Husain Asy-Syakir bin Abi Sujak, Fathul Qarib, Bandung: Syirkah Al-Ma'arif li Tabi wan Nasyrah, tt, hal. 14.

${ }^{19}$ Imam Muslim Juz I, Op.Cit, hal. 466.
} 
Puasa model ini, dilakukan sesuai dengan keikhlasan seseorang, artinya ibadah puasa dilakukan kapan saja, dan dimana saja tidak ada tempat dan waktu yang mengikatnya sebagai perbandingan. Hal ini berbeda dengan puasa yang dijalankan akibat pelanggaran ibadah haji.

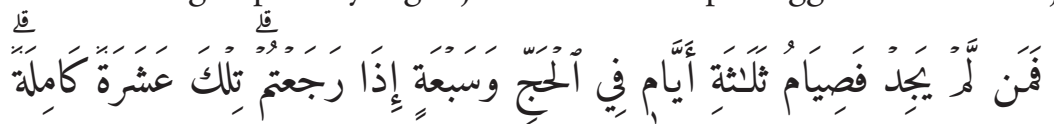
Artinya: Tetapi jika ia tidak menemukan '(binatang korban atau tidak mampu), maka wajib berpuasa tiga hari dalam masa haji dan tujuh hari (lagi) apabila kamu telah pulang kembali. ${ }^{20}$

Ayat tersebut di atas menunjukkan ada bentuk ibadah mahdah yang terikat tatacara puasa dan tempatnya, yaitu sebagian di tanah saja dalam bulan haji, sebagian dikerjakan di rumah setelah pulang dari ibadah haji.

Model ibadah ini disyariatkan dengan tujuan agar seorang hamba diberi kesempatan memilih tempat, waktu/kesempatan beribadah kepada Tuhan-nya, disesuaikan dengan kesanggupan dan kesempatan yang dimilikinya (keikhlasannya).

4) Ibadah Mahdah terikat batasan waktu (jalan peredaran matahari)

Bentuk ibadah puasa yang dilakukan pada hari-hari tertentu, sepanjang tahun, tidak terikat bulan tertentu. Misalnya puasa Senin dan Kamis.

Ini dilakukan oleh Rasul SAW:

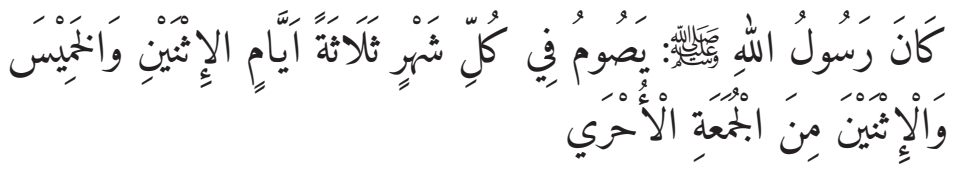

Artinya: Rasul saw puasa setiap bulan tiga hari, Senin dan Kamis, Senin dari Jumah yang lain. ${ }^{21}$

Puasa sunah Senin dan Kamis ini terikat hari-hari tertentu, yaitu hadi Senin dan hari Kamis tetapi tidak terikat bulan-bulan tertentu.

Model ibadah ini disyariatkan agar seseorang hamba dapat mengendalikan diri dalam kegiatan mingguan, mereka tidak terlupakan hari-

${ }^{20}$ QS. Al-Baqarah (2): 196.

${ }^{21}$ Al-Syan'any Juz 2, Op. Cit, hal. 169. 
hari dalam satu minggu untuk beribadah puasa sunnah bagi hamba kepada Tuhan-Nya.

5) Ibadah Mahdah yang tidak terikat waktu dan tempat, artinya suatu ibadah yang dapat dijalankan seluruh hari dalam satu tahun, tidak terikat bulan, bahkan dapat dijalankan secara spontan tanpa persiapan niat untuk menjalankannya. Contoh, ibadah puasa sunnah yang dilakukan Rasul saw dalam hadisnya:

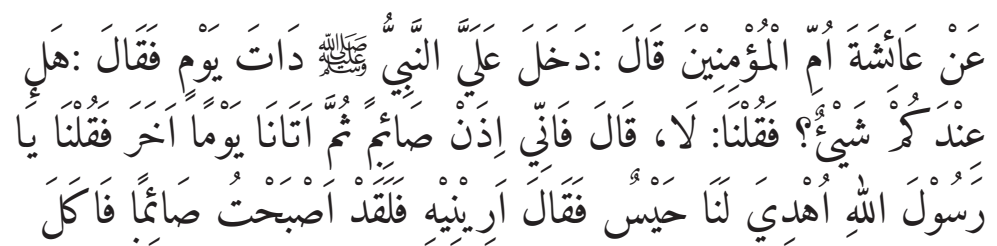

Artinya: Dari Aisyah Ummil Mukminin berkata: Rasul mendatangi aku suatu hari. Beliau bertanya, apakah kamu mempunyai sesuatu (makanan). Kami menjawab "tidak". Beliau berkata, Sebenarnya saya langsung tibatiba berpuasa. Kemudian suatu hari yang lain, Beliau mendatangi kami, Kami bertanya, "Wahai Rasul, hadiahkan kepada kami "haisun" (potongan kurma dicampur minyak samin)". Beliau menjawab, "Aku menunjukkannya, sungguh aku menjadi puasa, maka aku makan. ${ }^{22}$

Hadis tersebut menunjukkan bahwa ibadah puasa sesuai mahdah (tuntunan murni dari Rasul), tetapi dilakukan sewaktu-waktu tidak terkait waktu tertentu, setiap hari, bahkan untuk puasa sunah dilakukan tidak satu hari penuh), tetapi bersifat temporer. Artinya, niat puasa sunah diniati pada siang hari sebelum zawal sesuai kondisi yang diniatkan. Ini bertujuan untuk menjaga sikap toleransi hubungan sesama anggota keluarganya.

Model ini disyariatkan dengan tujuan agar seorang mukallaf dapat beribadah sesuai dengan pilihan waktu, yang bersifat temporer yang diniatkan, karena adanya sesuatu yang mendorong adanya niat berpuasa sunnah, sehingga waktu yang diawali atau mulai dijalankannya secara spontan (mulai waktu zuhur selama belum memakan sesuatu) yang dinilai sebagai ibadah puasa sunnah pada hari itu.

${ }^{22}$ Imam Muslim, Op.Cit, hal. 467. 


\section{Ibadah Ghairu Mahdah}

Yang dimaksud di sini adalah suatu bentuk ibadah yang didasari atas nas Al-Quran atau Al-Hadis (Syari'at Islam), akan tetapi tidak murni terikat pada aturan yang mengikat pada aturan Syariat Islam, kecuali ditentukan oleh syar'i. Model ibadah ini dapat dicontohkan sebagai berikut:

1) Zikir

Zikir adalah menyebut atau mengingat Allah SWT sebagai Tuhannya. Zikir diperintahkan Allah SWT, tetapi tidak diatur tatacaranya untuk melakukannya, sesuai firman Allah:

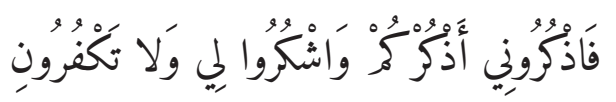

Artinya: Karena itu, ingatlah kamu kepada-Ku niscaya Aku ingat (pula) kepadamu, dan bersyukurlah kepada-Ku, dan janganlah kamu mengingkari (nikmat)-Ku. ${ }^{23}$

Allah memerintahkan kepada hamba-Nya agar ingat (zikir) kepadaNya namun tatacara zikir di sini tidak diatur secara detail, sehingga orang yang mengamalkannya, dengan leluasa, tidak terikat tempat, waktu atau bilangan khusus pada zikir tertentu.

Rasul juga memerintahkan umatnya untuk zikir kepada Allah SWT.

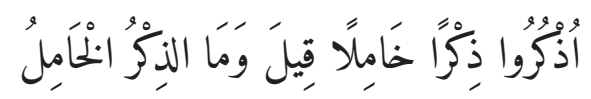

Artinya: Zikirlah dengan zikir khomil, dikatakan apakah zikir khomil, alkhomil yaitu zikir khofi (samar). ${ }^{24}$

Hadis ini memberikan kelonggaran dalam zikir samar, tidak terikat waktu, tempat atau dapat dilakukan dalam keadaan duduk, berdiri atau dimana saja dan kapan saja (kecuali terdapat ketentuan yang ditunjukkan hadis yang lain). Ini dilakukan agar seseorang berzikir sesuai dengan pilihan yang memadai dengan kemampuan dan keikhlasannya masing-masing.

2) Shadaqah

Shadaqah adalah adakalanya ditentukan oleh nas Al-Qur'an atau

\footnotetext{
${ }^{23}$ QS. Al-Baqarah (2): 152.

${ }^{24}$ Al-Suyuthy I, Op.Cit, hal. 37.
} 
Hadis, namun terdapat model shadaqah yang bebas, artinya tidak terdapat aturan yang mengikat, berhubungan dengan waktu atau tempat atau keadaan yang lain, sehingga seseorang dapat menjalankan shadaqah sesuai dengan kondisi orang itu sendiri. Misal dalam hadis yang berhubungan dengan shadaqah jariyah:

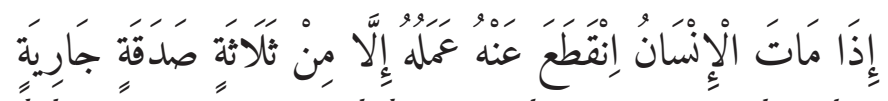

Artinya: Apabila manusia meninggal dunia, maka terputus amalnya kecuali tiga perkara: shadaqah jariyah, .... ${ }^{25}$

Dalam hadis ini menuturkan bahwa shadaqah jariyah belum ditentukan jenis barang, waktu dan tempat. Di sini menunjukkan kebebasan seseorang untuk bersedekah jariyah, mungkin dalam bentuk materi atau jasa atau yang lain. Pada prinsipnya nilai shadaqah mengalir terus walaupun ia sudah meninggal dunia. Ini bertujuan agar mukallaf bersedekah jariyah sesuai keadaan yang ada pada lingkungan kehidupan sehari-hari.

3) Berbakti kepada Orang Tua

Model ibadah berbakti kepada kedua orang tua ini diperintahkan oleh syariat Islam yang didasarkan atas nas Al-Qur'an dan Hadis, namun cara pengamalannya tidak terikat tempat, waktu atau tatacaranya sehingga pelaksanaannya mengikuti situasi dan kondisi yang ada.

Model ibadah berupa berbakti kepada kedua orang tua diperintahkan oleh Allah SWT:

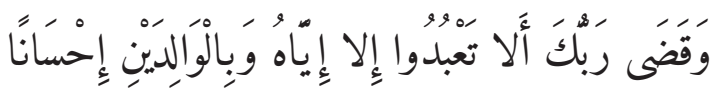

Artinya: Dan Tuhanmu telah memerintahkan supaya kamu jangan menyembah selain Dia dan hendaklah kamu berbuat baik pada ibu bapakmu dengan sebaik-baiknya. ${ }^{26}$

Berbuat baik kepada kedua orang tua diperintahkan oleh Allah, dan apabila dilaksanakan termasuk nilai ibadah. Ibadah model yang semacam ini dinamakan ibadah gairu mahdah karena tatacara berbakti

${ }^{25}$ Al-Suyuthy I, Op.Cit, hal. 35.

${ }^{26}$ QS. Al-Isra' (17): 23. 
kepada keduanya tidak diatur secara total, walaupun sebagian sudah ada petunjuk seperti larangan berbicara dengan lafad "ah" dan larangan untuk menghardiknya.

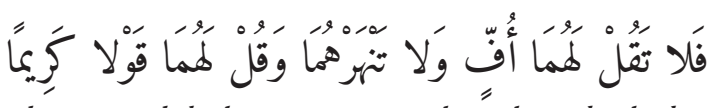

Artinya: maka sekali-kali janganlah kamu mengatakan kepada keduanya perkataan "ah" dan janganlah kamu membentak mereka dan ucapkanlah kepada mereka perkataan yang mulia. ${ }^{27}$

Tidak menunjukkan model yang lain maka model berbakti kepada keduanya dengan cara salam dengan cara yang telah ditulis pada ayat tersebut dapat juga dilakukan seperti berbakti dalam bentuk menyantuni, membantu kerepotan kepada keduanya.

Model berbakti kepada orang tua juga diperintakkan oleh Rasul SAW:

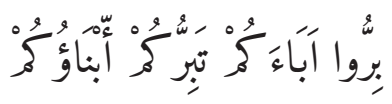

Artinya: berbaktilah kepada orang tuamu, maka anak-anakmu akan berbakti kepadamu. ${ }^{28}$

Model pengabdian kepada orang tua yang ditulis dalam hadis ini belum ditunjukkan tatacara, waktu dan tempatnya maka model pengabdian ini dinamakan ibadah gairu mahdah.

Model ibadah ini bertujuan agar para mukallaf dapat menentukan dan memilih jenis kebaktian seorang anak terhadap orang tuanya, disesuaikan jenis kegiatan yang mengarah kepada kebaktian terhadap orangtuanya.

4) Membaca Al-Quran

Membaca Al-Quran merupakan bentuk ibadah yang diperintahkan Allah dan Rasul saw. Firman Allah:

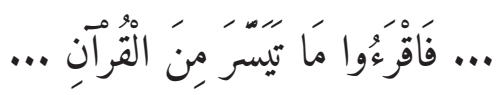

Artinya: maka bacalah apa yang mudah (bagimu) dari Al Quran dan

\footnotetext{
${ }^{27}$ QS. Al-Isra' (17): 23.

${ }^{28}$ As-Suyuthi Al Jamu’ al Shagir I, Op.Cit, hal. 125.
} 
dirikanlah salat. ${ }^{29}$

Rasul juga bersabda:

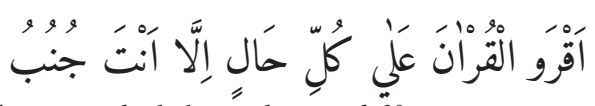

Artinya: Bacalah Al-Qur'an pada setiap hal, kecuali junub.

Membaca Al-Qur'an termasuk model ibadah yang disyariatkan Islam atas dasar nas Al-Qur'an dan Hadis sebagai ketaatan kepada Allah dan Rasul-Nya.

Membaca Al-Quran disyari'atkan yang tidak terdapat ikatan di dalamnya baik tempat, waktu, tetapi diisyaratkan tidak menanggung hadas (junub).

Model ibadah ini disyariatkan dengan tujuan agar seorang mukallaf dapat melakukan ibadah dengan membaca Al-Qur'an pada waktu yang diinginkan sesuai dengan kadar kemampuan dan kelonggaran waktu yang dimilikinya.

\section{KESIMPULAN}

Ibadah menurut pandangan pemahaman ilmu fiqih dapat dibagi menjadi dua yaitu ibadah mahdah, ibadah yang masih murni pengaturan tatacara, tempat dan waktunya. Sedangkan ibadah gairu mahdah yaitu model ibadah yang tidak diatur tatacara, penentuan waktu dan tempatnya.

1. Model ibadah mahdah disyariatkan terikat tempat, waktu dan tatacaranya, terikat tatacaranya, terikat batasan waktu atas peredaran matahari/bulan, terikat tatacaranya tetapi tidak terikat waktu, tempatnya.

2. Model ibadah gairu mahdah adalah bentuk ibadah yang tidak murni dalam ikatan pada syariat Islam, baik tempat, waktu maupun tatacaranya (kecuali disyariatkan).

Ibadah mahdah yang terikat tempat, waktu dan tatacaranya seperti ibadah haji, terikat waktu dan tatacaranya seperti ibadah salat, yang terikat tatacaranya seperti ibadah puasa sunah mutlak, ibadah haji. Gairu mahdah misalnya zikir, shadaqah, berbakti kepada kedua orang tua.

\footnotetext{
${ }^{29}$ QS. Al-Muzzammil (73): 20.

${ }^{30}$ Al-Suyuthi, Al-Jami' Al-Shagir, Op.Cit, hal. 52.
} 


\section{DAFTAR PUSTAKA}

Al-Qur'än dan Terjemahannya. Wakaf dan Pelayanan Tanah Suci, Raja Fuad bin Abdullah, Aziz Al-Saud, n.d.

Ghazali, Imam al, and Imam Abu Hamid Muhammad bin Muhammad. Ihya Ulumuddin. 1,2,3. Indonesia: Dar al-Ihya al- Kutub al-Arabiyah, n.d.

Kahlany, Al-Sayyid Al-Imam Muhammad bin Ismail al-, and Kemudian AlShan'any. Subulus Salam Juz 2. Bandung: Multazam Taba'ah wa al-Nasyrah, n.d.

Kahlany, Al-Sayyid Al-Imam Muhammad bin Ismail al-, and kemudian AlShan'any. Subulus Salam Juz 4. Bandung: Multazam al- Mathba'ah wa al-Nasyrah, n.d.

Malibari, Al-Syekh Zainuddin bin Abdul Azis bin Zainuddin al-. Irsyadu Al-

Ibad. Semarang: Maktabah wa Mathba'ah Thaha Putra, n.d.

Maraghi, Musthafa al-. Tafsir Al-Maragi Juz 10. Dar al- Fikri, n.d.

Marzuki. "Kemitraan Madrasah Dan Orang Tua Dalam Menanamkan Kedisplinan Ibadah Siswa Ma Asysyafi'iyah Kendari." Jurnal AlTádib Vol. 10 No. 2, Juli-Desember 2017 10, no. 2 (Juli-Desember 2017): 163-180.

Muslim, Imam. Shahih Muslim I. Indonesia: Dar al- Kitab al- Arabiyah, n.d.

—. Shahih Muslim I. Indonesia: Dar al- Ihya', n.d.

Nurlaili. "Pendidikan Ibadah Dalam Al-Quran." ITTIHAD I, no. 2 (JuliDesember 2017): 209-224.

Said, Suarning. "Wawasan Al-Qur'an Tentang Ibadah." Jurnal Syariah Dan Hukum Diktum 15, no. 1 (Juni 2017): 43-54.

Sholah, Ismail Abu Naser bin Hamid Al-Jauhari al-. Taju Al-Lughati wa Sihah Al-Arabiyah. n.d.

Sujak, Al-Imam Al-Alamah Ahmad bin Husain Asy-Syakir bin Abi. Fathul Qarib. Bandung: Syirkah al- Ma'arif li Tabi' wa al- Nasyrah, n.d.

Suyuthi, Al-Imam Jalaluddin Abdu Rahman Abi Bakar al-. Al-Jami Al-Shagir Juz 1, 2. Bandung Indonesia: Syirkah al- Ma'arif, n.d.

Sya'rany, Sayyid Abdul Wahab al-. Al-Minahu Al-Saniyah. Surabaya: Maktabah Balai Buku, $1400 \mathrm{H}$. 